\title{
Synthesis of activated spherical-like carbon (ASC) by gelatin soft templating route for inflammatory drug adsorption
}

\author{
Maria Ulfa $^{1^{*}}$ and Mega Viendrieana ${ }^{1}$ \\ ${ }^{1}$ Chemical Education Study Program, Faculty of Teacher Training and Education, Sebelas Maret University, \\ J1. Ir. Sutami 36A, Surakarta 57126, Central Java Indonesia
}

\begin{abstract}
.
Synthesis spherical like-carbon have been successfully ready done this work by using gelatin as natural soft template combined with spolyoxyethylene-Polyoxypropylene block copolymer as second template and sucrose as carbon precursor. After first reaction of gelatin, block copolymer and sucrose, the mixture have catalyzed by sulfuric acid followed by hydrothermal, evaporation, carbonization and pyrolized nitrogen atmosphere reaction. The spherical like-carbon then activated by potassium hydroxide for obtain activated spherical like-carbon (ASC) followed by filtering and drying. The characterization of activated spherical like-carbon (ASC) have been done by scanning electron microscopy and fourier transform of infra red. Activated spherical like-carbon (ASC) have applied as adsorbent of ibuprofen with initial concentration $0,1 \mathrm{mg} / \mathrm{g}$ and weight of carbon its is about $20 \mathrm{mg}$ adsorben. The adsorption kinetic investigated by uv-vis spectrophotometer. The morphology observation shows that activated spherical like-carbon (ASC) have spheric structure with the range size closely with $1-10 \mu \mathrm{m}$. The numerous carbonyl and hydroxyl functional group by FTIR observation was predicted increase as the interaction impact between ibuprofen and adsorbent. The interesting phenomenon was observed which is the increasing adsorption capacity of activated spherical like-carbon (ASC) as well equal as the increasing activation temperature.
\end{abstract}

Key Words: spheric carbon, soft template, gelatin, ibuprofen, activation temperature 


\section{2nd International Conference on Applied Research in}

\section{ENGINEERING SCIENCE \& TECHNOLOGY 18-20 October 2019

\author{
Budapest, Hungary
}

\section{INTRO}

Carbon microspheres have attracted much attention recently due the unique pore structure and size with narrow pore size distribution and as well as volley ball- like structure. The carbon microsphere was widely applied as catalyst, adsorbent, electrode and delivering carrier due to the smooth pore structure, high adsorption capacity, high surface area, and stability. In addition, most microspheric carbon is prepared based on alkaline conditions because of simplicity and eficiency (Wang, Xiufang et al. 2016; Xie, Yunyun et al. 2017). Drug delivery system (DDS) was required high surface area and large poreso accesible for drug molecule.

According to existing research to produce carbon microspheres with high surface area can be synthesized by hard template and soft template method. In this study the microspheres carbon synthesis was carried out by soft template method or colloidal cast method, which is a method used to synthesize carbon by using carbon structure directing agents in the form of surfactants or commonly known as solgel techniques (Ulfa, Maria. 2017). Synthesis of microspheres carbon was carried out using Polyoxyethylene-Polyoxypropylene Block Copolymer as a carbon structure directing agent under acidic conditions or as a template, and gelatin was used as a co-template.

Gelatin is a soluble protein that is a gel-making material, making it suitable for soft templates in the synthesis of microspheres carbon (solgel technique) because it has hydrophobic and hydrophilic tips in its structure which are characteristics of surfactants. The source of the raw material for gelatin usually comes from natural ingredients in the form of cow bones and skin, pig skin, and fish skin. So that in its role as a co-template in the synthesis of carbon microspheres this includes safe use and low cost. (A. Bigi et al., 2002; Li-Huei Lin et al., 2006; Y.Z. Zhang et al., 2006).

Activation of carbon is usually using acid,alkaline; or salt as activators. Some examples of commonly used activators are $\mathrm{HCl}, \mathrm{H}_{2} \mathrm{SO}_{4}, \mathrm{NaOH}, \mathrm{KOH}, \mathrm{ZnCl}_{2}, \mathrm{NaCl}$ (Wang, Jiacheng et al,. 2012). In this study carbon microspheres were activated with $\mathrm{KOH}$ solution. $\mathrm{KOH}$ 
2nd International Conference on Applied Research in acidity of carbon powder, able to open carbon pores so that the carbon surface area will be

ENGINEERING SCIENCE \& TECHNOLOGY

\section{8-20 October 2019}

\section{Budapest, Hungary}

higher, able to multiply micropore structures where the adsorbent with micropore pore size is more effective for the adsorption process, can suppress hydrocarbon impurities and impurities in carbon pores so that carbon absorption is greater, giving cavities on the surface of carbon, producing tar as fewer by-products (Jin Jin et al., 2010; Wang, Bin et al., 2016; Wang, Jiacheng. 2012; Zhou, Min et al., 2013). In this study, acid activators are not used because acid activators have a weakness which is corrosive so that it will damage and erode biological tissue if touched, the steam can cause irritation to the respiratory tract so it is less safe to use. $\mathrm{KOH}$ was used for the activation process in this study, because at low temperatures the activation with $\mathrm{KOH}$ was higher than $\mathrm{NaOH}$ (M.A. Lillo-Rodenas et al., 2001).

The factors that influence the activation process are activation time, activation temperature, particle size, activator ratio, and type of activator. Temperature activation affects the activation energy generated, the higher the activation temperature, the greater the energy produced. So that the activated carbon that is formed is getting better, and the activation temperature affects the final appearance of the product produced (S. Alonso et al., 2001).

Ibuprofen is a non-steroidal anti-inflammatory drug that is included in the derivative of arylacetic acid or propionic acid derivatives. Ibuprofen is an analgesic that is strong but with anti-inflammatory power that is not too strong. This drug is included in class II drugs, namely drugs with low solubility with high permeability. Ibuprofen functions to reduce pain due to inflammation. Side effects of using Ibuprofen are irritation of the digestive tract because the digestive tract quickly absorbs Ibuprofen with a half-life of 1.8-2 hours (Guindon, Josee et al., 2016; S. Albert, Kenneth et al., 1984). As time went on, the number of factories producing ibuprofen increased, resulting in higher levels of ibuprofen waste. Therefore, the high industrial waste of ibuprofen causes environmental pollution which will disrupt the ecosystem in the environment.

This research begins with the synthesis of microspheres carbon, followed by activation of microspheres carbon with $\mathrm{KOH}$ solution, then characterization, and then adsorption with ibuprofen. Adsorption is the process of absorption of a liquid material on the surface of a 
solid. The adsorption of ibuprofen on the surface of the microspheres carbon

2nd International Conference on Applied Research in

determine the adsorption capacity of the activated of the microspheres carbon in each

ENGINEERING. SCIENCE \& TECHNOLQGY predetermined variation. The adsorption capacity on microspheres carbon is relatively large, 18-20 October 2019

Budapest, Hungary

no studies have used microspheres for adsorption of ibuprofen. So that the use of microspheres carbon as carrier agents in the Drug Delivery System (DDS) has great potential. At the end of the study, it is expected to obtain microspheres carbon with fine pore structures, high adsorption surfaces, high bonds between adsorbents and adsorbates. So it is expected that the results of this study can be used as engineering to compile the DDS prototype.

\section{EXPERIMENTAL}

a. Materials

Polyoxyethylene-Polyoxypropylene Block Copolymer purchased in Sigma-Aldrich with properties related categories (3D Printing Materials for Research and Development, Amphiphilic Block Copolymers, Biochemicals and Reagents, Copolymers, Poly (ethylene glycol) and Poly (ethylene oxide), Synthetic Polymers for 3D Printing), description (Nonionic, contains 100ppm BHT), product line (BioReagent), form (Powder), suitable for cell culture. Ethanol (Ethyl Alcohol) purchased in Sigma-Aldrich, with grade (Laboratory Reagent) properties, vapor density (1.59 (vs water)), vapor pressure $\left(44.6 \mathrm{mmHg}\left(20^{\circ} \mathrm{C}\right)\right.$ ), assay ( $\geq 95.0 \%$ (vol.) $\leq 0.005 \%$ acidity (as $\mathrm{CH} 3 \mathrm{COOH}$ ). Purchased in Sigma-Aldrich gelatin, the synonym is gelatina, testing conforms to Pharmacopeia. Sucrose purchased in SigmaAldrich, with synonym properties $(\alpha-D-G l c-(1 \rightarrow 2)-\beta-D-F r u, \alpha-D-G l u c o p y r a n o s y l \quad \beta-D-$ fructofuranoside, $\beta$-D-Fructofuranosyl-a-D-glucopyranoside, $\mathrm{D}(+)$-Saccharose, Sugar), Related Categories (Biochemicals and Reagents, Carbohydrates, Cell Biology ), assay $(\geq 99.5 \%(\mathrm{GC})$ ). Acetic acid purchased in Sigma-Aldrich, with properties that are related categories (Acids, Acids \& Bases, Chemical Synthesis, Electronic Chemicals, Inorganic Acids, Materials Science, Micro / NanoElectronics, Synthetic Reagents), description (Nominally 95-98\% H2SO4), assay (99.999\%). KOH purchased in Sigma-Aldrich, with properties that are related categories (Acids \& Bases, Bases, Chemical Synthesis, Inorganic Bases, Synthetic Reagents), pH (14 (56 g / 1, $\left.\mathrm{H}_{2} \mathrm{O}, 20^{\circ} \mathrm{C}\right)$ ), specifications (Assay 
(acidimetric, $\mathrm{KOH}$ ): $\geq 85.0 \%$ ). Ibuprofen purchased in Sigma-Aldrich, with proper

2nd International Conference on Applied Research in are related categories (Biochemicals and Reagents, Cell Biology, Cell Signaling Enzymescon

ENGINEERING SCIENCE \& TECHNOLOGY

Cell Signaling and Neuroscience, Cyclooxygenase, Enzyme Inhibitors, and Substrates),

18-20 assats

properties that are related categories (Reagent Plus Solvent Grade Products, ACS and Reagent Grade Solvents, Amber Glass Bottles), assay ( $\geq 99 \%)$, water insoluble. Aquades.

\section{b.Microspheres Carbon Synthesis}

Synthesis of microspheres carbon begins by preparing a powder of PolyoxyethylenePolyoxypropylene Block Copolymer, and making ethanol solution with a ratio of ethanol and water with a ratio of 1.5: 11.7: 3.9. The next step is dripping ethanol into PolyoxyethylenePolyoxypropylene Block Copolymer using the burette until the ethanol runs out, then stirring the mixture. Next add gelatin and sucrose to a ratio of 0.4 to the solution of PolyoxyethylenePolyoxypropylene Block Copolymer while stirring and a clear solution is produced. Then, $\mathrm{H}_{2} \mathrm{SO}_{4}$ solution is made from sucrose plus aquades and droplets of concentrated $\mathrm{H}_{2} \mathrm{SO}_{4}$ solution with a ratio of $0.3: 1.5: 1.5$. Furthermore, $\mathrm{H}_{2} \mathrm{SO}_{4}$ solution is dropped into a clear solution with a burette while stirring. After all the Polyoxyethylene-Polyoxypropylene Block Copolymer has been dropped, sucrose is added to the mixed solution while stirring and a clear mixture will be produced. The clear mixture is inserted into the hydrothermal reactor while in the oven, then cools it and becomes a brown mixture. Furthermore, the chocolate mixture is oven-heated in hydrothermal and oven again at $160^{\circ} \mathrm{C}$ (partial carbonization). After that, the mixture is poured into the porcelain exchange rate and oven until it is obtained dry black solid. Black solids are carbonized in furnaces with nitrogen or argon gas, becoming fine black solids. The fine black solid is washed with distilled water, then filter with a vacuum filter and observe it. Washing is done several times until there is no white sediment, then the solid is dried in the oven overnight. The sample produced is labeled SMC. 


\section{2nd International Conference on Applied Research in}

\section{ENGINEERING SCIENCE \& TECHNOLOGY}

\section{8-20 October 2019 \\ Budapest, Hungary}

b.Activation of SMC

Activation of the microspheres carbon was initiated by mixing SMC powder and potassium hydroxide $(\mathrm{KOH})$ solution with a concentration of $10 \%$ while stirring for 30 minutes at room temperature $\left(25^{\circ} \mathrm{C}\right)$. Then the mixture of SMC with $10 \% \mathrm{KOH}$ solution was left to stand for 24 hours with temperature variations $-9^{\circ} \mathrm{C}, 29^{\circ} \mathrm{C}$, and $35^{\circ} \mathrm{C}$. After that, the mixture that has been left idle is filtered with Whatmann 42 filter paper, resulting in filtrate and solids. Then

the solid is heated in the oven to dry. The results of this activation will be used for adsorption of ibuprofen and for characterization. Characterization is done by using SEM to determine the size and morphology of the particles, and FTIR to find out the functional groups in activated SMC. The sample produced is labeled ASMC (-9oC); ASMC (29oC); ASMC $(350 \mathrm{c})$.

\section{b. Adsorption of Ibuprofen}

Adsorption of ibuprofen was started by dissolving ibuprofen powder with hexane solvent until it obtained a solution of ibuprofen with a concentration of $100 \mathrm{ppm}$. Then take $50 \mathrm{ml}$ of the 100 ppm ibuprofen solution and put it in the beaker. Add $20 \mathrm{mg}$ of ASMC to the glass cup containing a solution of ibuprofen, while sterilizing at room temperature $\left(25^{\circ} \mathrm{C}\right)$. Then take $3 \mathrm{~mL}$ of sample solution every 5 minutes' intervals 15 times and take a UV-Vis spectrophotometer at a wavelength of $272 \mathrm{~nm}$. So that the UV-Vis graph will appear from the sample, namely 100 ppm ibuprofen solution.

\section{c. Characterization of ASMC}

The characterization of ASMC was carried out through surface area analysis techniques with scanning electron microscope (SEM), and functional group analysis techniques with fourier transform infrared (FTIR). SEM analysis using a JEOL JSM-700 microscope at $15.0 \mathrm{kV}$. FTIR analysis using Bruker Vertex 70 spectroscop with wavelengths from 4000-500 cm-1. Whereas to measure absorbance in adsorbed samples, an UV-Vis spectrophotometer was performed with the U-2000 model from Hitachi Japan at a wavelength of $272 \mathrm{~nm}$. 


\section{2nd International Conference on Applied Research in}

\section{ENGINEERING SCIENCE \& TECHNOLOGY}

\section{8-20 October 2019 \\ Budapest, Hungary}

\section{III.RESULT AND DISCUSSION}

a.Activation of Microspheres Carbon (SMC)

ASMC produced after activation with $\mathrm{KOH}$ solution at $-9^{\circ} \mathrm{C} ; 29^{\circ} \mathrm{C} ; 35^{\circ} \mathrm{C}$ will be used for adsorption with $100 \mathrm{ppm}$ ibuprofen solution, and for characterization using surface analysis techniques with SEM and functional group analysis techniques with FTIR.

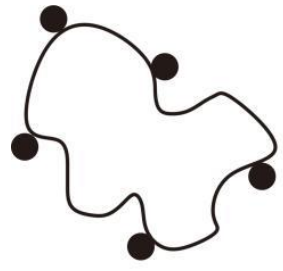

(a)

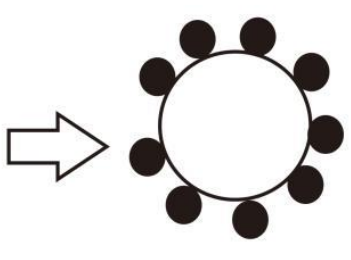

(b)

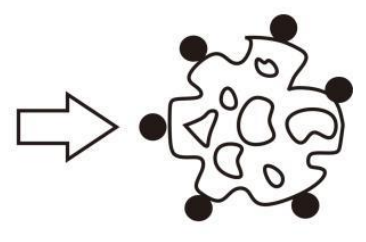

(c)

Figure 1. Illustration of structural changes (a) ASMC $-\left(-9^{\circ} \mathrm{C}\right)$, (b) ASMC (29oC), (c) ASMC (35oC)

From Fig 1 it can be seen that the activation process at temperatures of $-9^{\circ} \mathrm{C}$ and $35^{\circ} \mathrm{C}$ causes damage to the carbon structure, but more severe damage occurs to the activation of carbon at a temperature of $-9^{\circ} \mathrm{C}$. While the activation of carbon at $29^{\circ} \mathrm{C}$ does not cause carbon structure desctruction. The resulting ASMC is surrounded by potassium aggregates, water particles $\left(\mathrm{H}_{2} \mathrm{O}\right)$, impurities, and other particles. 


\section{2nd International Conference on Applied Research in}

\section{ENGINEERING SCIENCE \& TECHNOLOGY}

\section{8-20 October $2019 \quad$ Budapest, Hungary}

Table 1. Table of influence of SMC activation temperature on mass before activation and mass after activation

\begin{tabular}{ccc}
\hline Sampel & \multicolumn{2}{c}{ Activation Mass } \\
\cline { 2 - 3 } & Before $(\mathrm{g})$ & After $(\mathrm{g})$ \\
\hline $\mathrm{ASMC}\left(-9^{\circ} \mathrm{C}\right)$ & 0,30 & 0,74 \\
$\mathrm{ASMC}\left(29^{\circ} \mathrm{C}\right)$ & 0,30 & 0,82 \\
$\mathrm{ASMC}\left(35^{\circ} \mathrm{C}\right)$ & 0,30 & 0,75 \\
\hline
\end{tabular}

From the table above, the results show that there is an increase in ASMC mass. The highest increase in mass of ASMC occurs at $29^{\circ} \mathrm{C}$ activation, this is estimated because ASMC at $29^{\circ} \mathrm{C}$ has the right energy to activate SMC, potassium aggregates; water particles $\left(\mathrm{H}_{2} \mathrm{O}\right)$; impurity; and the other particles attached to the surface of the SMC are the most numerous and evenly distributed compared to ASMC at temperatures of $-9^{\circ} \mathrm{C}$ and $35^{\circ} \mathrm{C}$. Whereas the

mass increase in ASMC temperature $-9^{\circ} \mathrm{C}$ and $35^{\circ} \mathrm{C}$ only shows a very small difference and the mass increase is not as much as ASMC $(290 \mathrm{C})$, this is estimated because ASMC $-\left(-9^{\circ} \mathrm{C}\right)$ and ASMC (35oC) carbon structure damage so that the aggregate potassium; water particles $\left(\mathrm{H}_{2} \mathrm{O}\right)$; impurity; and other particles attached to the SMC surface are only a little or not as much as ASMC (29oC). Potassium aggregates that are attached or trapped on the surface of the SMC can occur because the size of the SMC pores is less than $2 \mathrm{~nm}$ (micropore), whereas it is estimated that the average radius of the element $\mathrm{K}$ is $0.23 \mathrm{~nm}$. 


\section{2nd International Conference on Applied Research in}

\section{ENGINEERING SCIENCE \& TECHNOLOGY}

\section{8-20 October 2019 \\ Budapest, Hungary}

a.Adsorption of Ibuprofen

The adsorption process of ibuprofen is done by mixing ibuprofen and SMC solution while stirring at room temperature $\left(25^{\circ} \mathrm{C}\right)$. Then take $3 \mathrm{~mL}$ of sample solution every 5 minutes at the interval of 15 times. The sample solution that has been taken will be analyzed using a uvvis spectrophotometer at a wavelength of $272 \mathrm{~nm}$. From the results of the analysis obtained absorbance values for each temperature variation $-9^{\circ} \mathrm{C} ; 29^{\circ} \mathrm{C} ; 25^{\circ} \mathrm{C}$. Then the absorbance data is converted into concentration with the help of the equation obtained from the standard solution curve, the standard solution curve equation obtained is $0.0257 \mathrm{x}+0.0199$ with $\mathrm{R}^{2}=0.9813$.

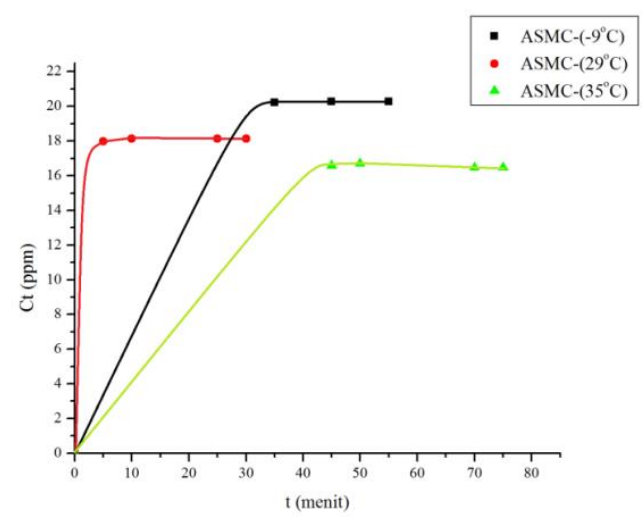

Figure 2. Graph of adsorption performance from ASMC (-9oC), ASMC (29oC), ASMC $(35 \mathrm{oC})$

From the graph above it can be seen that ASMC $(-90 C)$ has the highest equilibrium concentration of $20.22 \mathrm{ppm}$, while ASMC (35oC) has the lowest equilibrium concentration of $16.58 \mathrm{ppm}$. The higher the temperature of the carbon activation of the microsphere produces the lower the equilibrium concentration. But ASMC $(29 \circ C)$ reaches the equilibrium concentration at the fastest time, namely in the 5th minute, while ASMC $(-90 C)$ and ASMC (35oC) require a long time to reach equilibrium concentrations which are 35 and 45 minutes respectively. This is expected to occur because the temperature of $29^{\circ} \mathrm{C}$ is the right 


\section{2nd International Conference on Applied Research in}

\section{ENGINEERING SCIENCE \& TECHNOLOGY}

\section{8-20 October $2019 \quad$ Budapest, Hungary}

temperature for activation, so the right energy is generated to activate it, so that the resulting adsorption surface is high with more regular carbon pores.

Table 2. Table of effect of SMC activation temperature on maximum adsorption capacity

$$
\left(q_{\max }\right)
$$

\begin{tabular}{cc}
\hline Sampel & $\boldsymbol{q}_{\max }(\mathbf{m g} / \mathbf{g})$ \\
\hline ASMC $(-9 \circ \mathrm{oC})$ & 56.96 \\
ASMC $(29 \circ \mathrm{oC})$ & 58.47 \\
ASMC $(35 \circ \mathrm{oC})$ & 59.50 \\
\hline
\end{tabular}

The table above shows that the higher the activation temperature produces the higher adsorption capacity $\left(q_{\max }\right)$. It is estimated that because the higher the activation temperature will produce higher energy, so that the resulting $q_{\max }$ is higher too.

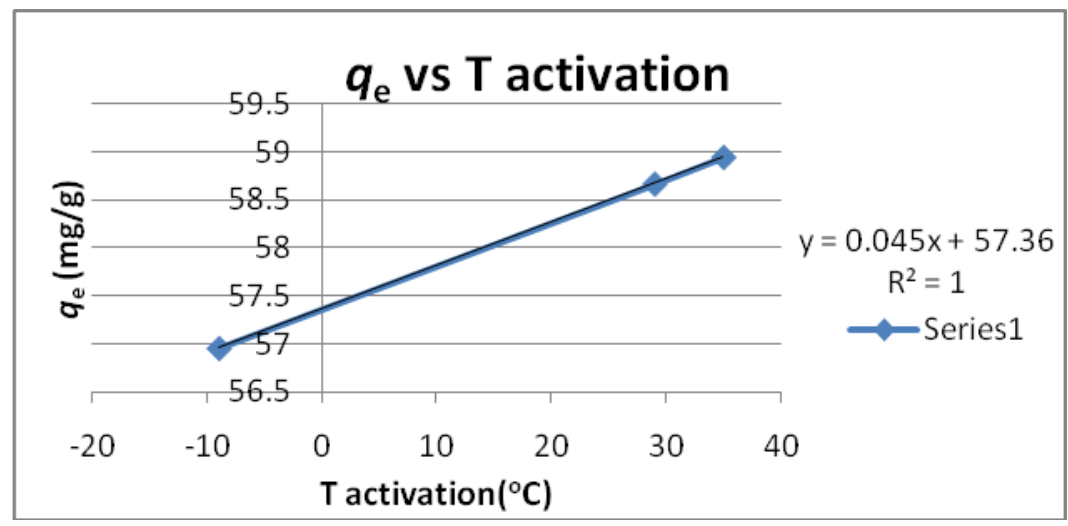

Figure 3. Graph of the relationship between adsorption capacity at equilibrium $\left(q_{\mathrm{e}}\right) \mathrm{in} \mathrm{mg} / \mathrm{g}$ and the activation temperature of $\mathrm{SMC}$ in ${ }^{\circ} \mathrm{C}$

From the graph shows that there is a relationship between adsorption capacity when balanced with the SMC activation temperature, which is the higher the activation temperature, the higher the adsorption capacity when balanced. The relationship between the two is shown by 


\section{2nd International Conference on Applied Research in}

\section{ENGINEERING SCIENCE \& TECHNOLOGY}

\section{8-20 October 2019 \\ Budapest, Hungary}

a graph which produces $\mathrm{R}^{2}=1$. Because the activation temperature affects the amount of damage to the carbon structure produced. The energy produced is higher along with the higher activation temperature, so that the resulting bond gets stronger. The impact velocity that occurs between carbon molecules at each temperature varies, so the adsorption capacity produced will also be different. Where, the higher the activation temperature will result in a greater impact speed with greater intensity, and will cause the adsorption capacity of the ibuprofen molecule to increase.

a. Characterization Results

i. $\quad$ Fourier transform infrared (FTIR) Characterization Results



Figure 4. Graph of results of characterization with FTIR from ASMC 


\section{2nd International Conference on Applied Research in}

\section{ENGINEERING SCIENCE \& TECHNOLOGY}

\section{8-20 October 2019 \\ Budapest, Hungary}

According to research conducted by Chin-San Wu (2007) in the range of wavelengths between 3700-2800 $\mathrm{cm}^{-1}$, it shows a group of functions $-\mathrm{OH}$. According to Min Li's (2011) experiment at $1100-3570 \mathrm{~cm}^{-1}$ shows the functional group $\mathrm{O}=\mathrm{C}-\mathrm{OH}$. Whereas in the Xiaoming Sun (2004) experiment at $1620 \mathrm{~cm}^{-1}$ showed double bonds $\mathrm{C}=\mathrm{C}$ and $1710 \mathrm{~cm}^{-1}$ were $\mathrm{C}=\mathrm{O}$, and in experiments conducted by Abdel-Naseer (2009) double bonds $\mathrm{C}=\mathrm{C}$ appeared at length wave $1660-1430 \mathrm{~cm}^{-1}$. In the research conducted by $\mathrm{J}$ Rumanos, the $\mathrm{C}-\mathrm{OH}$ group appeared at wavelengths between $3429 \mathrm{~cm}^{-1}$ to $1630 \mathrm{~cm}^{-1}$. Then in the K.Y.Foo (2011) study at $2357 \mathrm{~cm}^{-1} \mathrm{C} \equiv \mathrm{C}$ bonds appeared. And according to R.G Snyder (1960) K-OH groups appear at wavelengths of 4000-300 $\mathrm{cm}^{-1}$. According to Xuefei Li (2009), the adsorption peak at $1335 \mathrm{~cm}^{-1}$ appeared $\mathrm{C}-\mathrm{N}$.

In this study, FTIR results were obtained which showed that $\mathrm{K}-\mathrm{OH}$ groups appeared at wavelengths of 432.50-492.52 $\mathrm{cm}^{-1}$. At wavelength $1558.92-1556.28 \mathrm{~cm}^{-1} \mathrm{C}=\mathrm{C}$ group appears, then $\mathrm{C}-\mathrm{OH}$ group appears at a wavelength of 2040.44-1694.17 $\mathrm{cm}^{-1}$. Then at 2337.27-2200.80 $\mathrm{cm}^{-1}$. In addition, at a wavelength of about $3500 \mathrm{~cm}^{-1}$, the $-\mathrm{OH}$ group and $\mathrm{O}=\mathrm{C}-\mathrm{OH}$ appear. The $\mathrm{C} \equiv \mathrm{C}$ bond appears at $2500-2250 \mathrm{~cm}^{-1}$. The $\mathrm{C}=\mathrm{O}$ bond appears at 1750 $1500 \mathrm{~cm}^{-1}$. And the $\mathrm{C}-\mathrm{N}$ group appears at $1500-1250 \mathrm{~cm}^{-1}$. From the results of the FTIR above, the higher the activation temperature results in the $-\mathrm{OH}$ group; $\mathrm{O}=\mathrm{C}-\mathrm{OH} ; \mathrm{C}-\mathrm{OH}$; $\mathrm{C}=\mathrm{O}$; and $\mathrm{C}-\mathrm{N}$ decreases. Whereas for the $\mathrm{C} \equiv \mathrm{C}$ group more and more along with the higher activation temperature. The $\mathrm{C}-\mathrm{N}$ group tends not to change as the activation temperature changes, the $\mathrm{C}-\mathrm{N}$ group at each temperature is relatively the same. But most $\mathrm{K}-\mathrm{OH}$ groups are found in ASMC $(29 \mathrm{oC})$, thus indicating that at the activation temperature of $29^{\circ} \mathrm{C}$ the $\mathrm{K}-$ $\mathrm{OH}$ group that envelops carbon plays a role in helping the adsorption process and at $29^{\circ} \mathrm{C}$ the right temperature for carbon activation. 
2nd International Conference on Applied Research in ENGINEERING SCIENCE \& TECHNOLOGY 18-20 October 2019

Budapest, Hungary

ii. Characterization of scanning electron microscope (SEM)

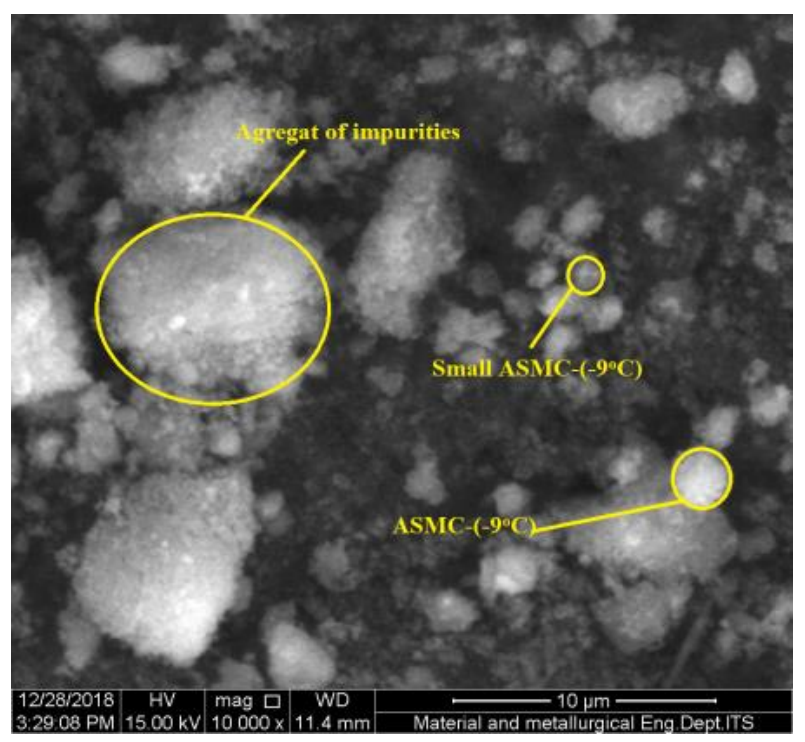

(a)

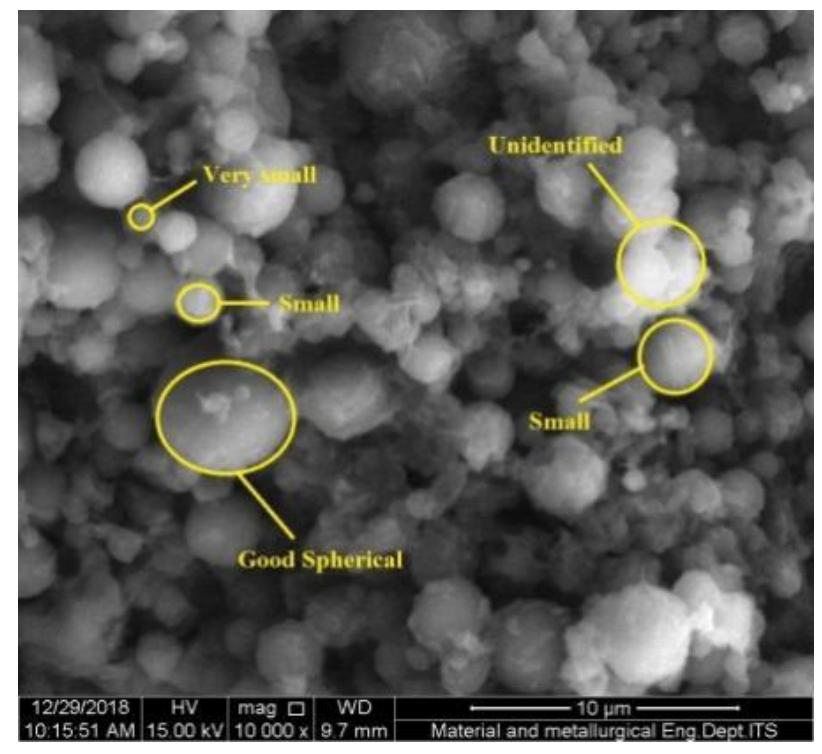

(b) 


\section{2nd International Conference on Applied Research in}

\section{ENGINEERING SCIENCE \& TECHNOLOGY}

\section{8-20 October 2019}

\section{Budapest, Hungary}



(c)

Figure 5. Results of characterization with SEM from (a) ASMC (-9oC), (b) ASMC (29oC), (c) ASMC (35oC)

From the results of the characterization with SEM, the ASMC structure damage occurs at activation with a temperature of $-9^{\circ} \mathrm{C}$ and $35^{\circ} \mathrm{C}$, it can be seen that the ASMC- $(-9 \circ \mathrm{C})$ has the most damaged structure not rounded again, whereas ASMC (35oC) occurs damage to structures but not as severe as that of ASMC $-\left(-9^{\circ} \mathrm{C}\right)$. ASMC $(35 \circ \mathrm{oC})$ is damaged but is still round in shape with a non-smooth surface, but like a rounded surface, the surface is hollow and uneven. The damaged surface is covered in very little potassium aggregate; water particles $\left(\mathrm{H}_{2} \mathrm{O}\right)$; impurity; and other particles. In some parts severe damage is seen but not significant compared to ASMC- $\left(-9^{\circ} \mathrm{C}\right)$. In ASMC $(29 \mathrm{oC})$ there is nothing significant structural destruction which is the structure of ASMC $(29 \mathrm{oC})$ still looks round with a smooth surface covered with potassium aggregates; water particles $\left(\mathrm{H}_{2} \mathrm{O}\right)$; impurity; and other particles. The ASMC $-\left(-9^{\circ} \mathrm{C}\right)$ sample not completely covered by impurities. 


\section{2nd International Conference on Applied Research in}

\section{ENGINEERING SCIENCE \& TECHNOLOGY}

\section{8-20 October 2019 \\ Budapest, Hungary}

Table 3. Table number of ASMC structures that are damaged and not damaged after being activated at $-9^{\circ} \mathrm{C}, 29^{\circ} \mathrm{C}, 35^{\circ} \mathrm{C}$

\begin{tabular}{ccl}
\hline Sampel & $\sum$ Damaged (\%) & $\sum$ Undamaged (\%) \\
\hline ASMC (-9oC) & $85 \%$ & $3 \mu \mathrm{m}=5 \%$ \\
& $1 \mu \mathrm{m}=10 \%$ \\
& & $5 \mu \mathrm{m}=3 \%$ \\
ASMC (29oC) & $2 \mu \mathrm{m}=13 \%$ \\
& $2 \mu \mathrm{m}=22 \%$ \\
$1 \mu \mathrm{m}=45 \%$ \\
$0,5 \mu \mathrm{m}=8 \%$ \\
$0,1 \mu \mathrm{m}=7 \%$ \\
\\
& & $4 \mu \mathrm{m}=15 \%$ \\
& $3 \mu \mathrm{m}=21 \%$ \\
& $2 \mu \mathrm{m}=35 \%$ \\
& $1 \mu \mathrm{m}=9 \%$ \\
& & \\
& &
\end{tabular}

From the table above, it can be seen that the greatest damage to the ASMC structure occurs at the activation temperature of $-9^{\circ} \mathrm{C}$, and the smallest damage occurs at $29^{\circ} \mathrm{C}$ activation temperature, while at $35^{\circ} \mathrm{C}$ the activation temperature also breaks down the structure but is still relatively small. In ASMC (29oC) it produces a structure with a size between $0.1-3 \mu \mathrm{m}$ but is dominated by a size of $1 \mu \mathrm{m}$, the size is smaller than ASMC $-\left(-9^{\circ} \mathrm{C}\right)$ and ASMC $(35 \mathrm{oC})$. From the table, it is known that ASMC $-\left(-9^{\circ} \mathrm{C}\right)$ produces $85 \%$ of the damaged structure, so the number of undamaged ASMC is very small and predominantly $1 \mu \mathrm{m}$ in size. Whereas in ASMC $(35 \circ \mathrm{C})$ the number of undamaged structures measuring between $4-1 \mu \mathrm{m}$ is dominated by $2 \mu \mathrm{m}$ size. 


\section{2nd International Conference on Applied Research in}

\section{ENGINEERING SCIENCE \& TECHNOLOGY \\ 18-20 October 2019 \\ Budapest, Hungary}

\section{CONCLUSION}

From this research, it can be concluded that the synthesis of microspheres carbon with the soft template method and activated with $\mathrm{KOH}$ at $29^{\circ} \mathrm{C}$ produces $\mathrm{ASMC}$ which has a high surface area and adsorption capacity. FTIR results show that clusters that appear on ASMC

include $-\mathrm{OH} ; \mathrm{O}=\mathrm{C}-\mathrm{OH} ; \mathrm{C}-\mathrm{OH} ; \mathrm{C}=\mathrm{O} ; \mathrm{C}-\mathrm{N} ; \mathrm{C} \equiv \mathrm{C} ; \mathrm{C}-\mathrm{N} ; \mathrm{K}-\mathrm{OH}$. Then from the SEM results it shows that ASMC- $\left(-9^{\circ} \mathrm{C}\right)$ and ASMC $(35 \circ \mathrm{oC})$ damage to carbon structure, where in ASMC$\left(-9^{\circ} \mathrm{C}\right)$ carbon is the most damaged. Damage to the carbon structure is at least at ASMC $(29 \mathrm{oC})$, so that the temperature of $29^{\circ} \mathrm{C}$ is the right temperature to do SMC activation. The amount of $q_{\max }$ is directly proportional to the higher activation temperature. Therefore, the results of this study can be used as an adsorbent in the control of ibuprofen waste in the environment and can be used as a basis for making drug delivery system (DDS) prototypes. But to deepen its use in DDS, further research is needed.

\section{Acknowledgements}

Our research was financially supportedby the Directorate General of Higher Education Indonesia under the Post Doctoral Grant 2018 (grant number 718/UN27.21/PN/2019). 


\section{2nd International Conference on Applied Research in}

\section{ENGINEERING SCIENCE \& TECHNOLOGY}

\section{8-20 October 2019 \\ Budapest, Hungary}

\section{REFERENCES}

(1) A. Bigi, G. Cojazzi, S. Panzavolta, N. Roveri, K. Rubini. 2002. Stabilization of gelatin films by crosslinking with genipin. Biomaterials 23, 4827-4832.

(2) Abdel-Nasser et al,. 2009. An insight into the KOH activation mechanism through the production of microporous activated carbon for the removal of $\mathrm{Pb}^{2+}$ cations. Applied Surface Science 255, 3723-3730.

(3) Chin-San Wu, Hsin-Tzu Liao. 2007. Study on the preparation and characterization of biodegradable polylactide/multi-walled carbon nanotubes nanocomposites. Polymer 48, 4449-4458.

(4) Guindon, Josee, Andre De Lean, Pierre Beaulieu. 2016. Local interactions between anandamide, an endocannabinoid, and ibuprofen, a nonsteroidal anti-inflammantory drug, in acute an inflammantory pain. Pain 121, 85-93.

(5) J Rumanos, et al,. 2012. Nanospace engineering of $\mathrm{KOH}$ activated carbon.IOP Publishing, Nanotechnology 23.

(6) Jin Jin, Shunsuke Tanaka, Yasuyuki Egashira, Norikazu Nishiyama. 2010. KOH activation of ordered mesoporous carbons prepared by a soft-templating method and their enhanced electrochemical properties. Carbon 48, 1985-1989.

(7) K.Y. Foo, B.H. Hameed. 2011. Preparation of oil palm (Elaeis) empty fruit bunch activated carbon by microwave-assisted $\mathrm{KOH}$ activation for the adsorption of methylene blue. Desallination 275, 302-305.

(8) Li, Min et al,. 2011. Hydrotermal synthesis,characterization, and $\mathrm{KOH}$ activation of carbon spheres from glucose. Carbohydrat Research 346, 999-1004.

(9) Li-Huei Lin, Keng-Ming Chen. 2006. Preparation and surface activity of gelatin derivative surfactants. Colloids and Surfaces A : Physicochem. Eng. Aspects 272, 8-14.

(10) M.A. Lillo-Rodenas, D. Lozano-Castello, D. Cazorla-Amoros, A. Linares-Solano.

2001. Preparation of activated carbons from Spanish anthracite II. Activation by NaOH. Carbon 39, 751-759. 


\section{2nd International Conference on Applied Research in}

\section{ENGINEERING SCIENCE \& TECHNOLOGY}

\section{8-20 October 2019 \\ Budapest, Hungary}

(11) R.G Snyder et al,. 1960. Vibration Spectrum of Crystalline Potassium Hydroxide. The Journal of Chemical Physics, Vol. 33, No. 4.

(12) S. Albert, Kenneth, Charlene M. Gernaat. 1984. Pharmacokinetics of ibuprofen. The American Journal of Medicine.

(13) S. Alonso, A. Palomo. 2001. Alkaline activation of metakaolin and calcium hydroxide mixtures: influence of temperature, activator concentration and solids ratio. Materials Letters 47, 55-62.

(14) Ulfa, Maria. 2017. Karbon Mesopori dalam Dunia Global. Jurnal Kimia dan Pendidikan Kimia, Vol 2, No 1.

(15) Wang, Bin, Jianhui Qiu, Huixia Feng, Eiichi Sakai, Takao Komiyama. 2016. KOH-activated nitrogen doped porous carbon nanowires with superior performance in supercapacitors. Electrochimica Acta.

(16) Wang, Jiacheng, Stefan Kaskel. 2012. KOH activation of carbon-based materials for energy storage. Journal of Materials Chemistry.

(17) Wang, Xiufang et al., 2016. Direct Synthesis of Carbon Michrospheres Under Acidic and Fenofibrate release. Materials Letters.

(18) Xiaoming Sun, Yadong Li. 2004. Colloidal Carbon Spheres and their Core/Shell Structures with Noble-Metal Nanoparticles. Angewandte Chemie.

(19) Xie, Yunyun et al., 2017. Fibrous N-doped hierarchical porous carbon microspheres: Synthesis and adsorption performance. Chemical Engeneerin Journal.

(20) Xuefei Li, Jian Zhang, Longhai Shen, Yanmei Ma, Weiwei Lei, Qiliang Cui, Guangtian Zhou. 2009. Preparation and characterization of graphitic carbon nitride through pyrolysis of melamine. Applied Physics A Materials Science \& Processing. 
2nd International Conference on Applied Research in ENGINEERING SCIENCE \& TECHNOLOGY

(21) Y.Z. Zhang, J. Venugopal, Z.-M. Huang, C.T. Lim, S. Ramakrishna. 2006. Crosslinking of the electrospun gelatin nanofibers. Polymer 47, 2911-2917.

(22) Zhou, Min, Fan Pu, Zhao Wang, Shiyou Guan. 2013. Nitrogen-doped porous carbons through $\mathrm{KOH}$ activation with superior performance in supercapacitors. Carbon 68, 185-194. 